\title{
Association of 8-hydroxy-2'-deoxyguanosine with various demographic and biochemical parameter in a group of hemodialysis patients
}

\author{
Fatemeh Goli $^{\circledR}$, Hamid Nasri* ${ }^{\circledR}$ \\ Department of Nephrology, Isfahan University of Medical Sciences, Isfahan, Iran
}

Correspondence to:

Prof. Hamid Nasri, hamidnasri@ yahoo.com, hamidnasri@med. mui.ac.ir

Received: 4 June 2020 Accepted: 10 July 2020 ePublished: 1 Aug. 2020

Keywords: End-stage renal disease, Oxidative stress, 8-hydroxy-2'-deoxyguanosine, Hemodialysis

\begin{abstract}
Introduction: Hemodialysis (HD) patients have elevated markers of oxidative stress which is contributed to increased mortality.

Objectives: The aim of this study was to determine the association of 8-hydroxy-2'-deoxyguanosine (8$\mathrm{OHdG}$ ) as a marker of oxidative stress with various demographic and biochemical parameters in $\mathrm{HD}$ patients.

Patients and Methods: Eighty-five HD patients (58 men and 27 women; mean \pm SD of age was $62.8 \pm$ 13.76 years) who were under HD therapy for at least six months and did not have a systemic infection were enrolled in the study. Serum 8-OHDG was measured by ELISA (enzyme-linked immunosorbent assay) method. Additionally levels of vitamin D, magnesium, and intact parathyroid hormone (PTH) were measured with standard kits. Other clinical and biochemical variables were gathered from patients' files. Results: The result showed no significant correlation between serum levels of 8-OHDG with measured biochemical and demographic parameters. However, in HD patients with diabetes and hypertension (or combined), a significant reverse correlation between serum albumin and 8-OHdG was detected. Conclusion: In the age group under 40 years, we found a positive and significant correlation between albumin and $8-\mathrm{OHdG}$. This finding requires further investigation to determine relationship between serum $8-\mathrm{OHdG}$ levels and serum albumin types as reduced and oxidized forms.
\end{abstract}

\begin{abstract}
Citation: Goli F, Nasri H Association of 8-hydroxy$2^{\prime}$-deoxyguanosine with various demographic and biochemical parameter in a group of hemodialysis patients. J Prev Epidemiol. 2020;5(1):e06 doi:10.34172/jpe.2020.06
\end{abstract}

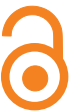

\section{Introduction}

Oxidative stress is defined as an imbalance between oxidant production such as reactive oxygen, nitrogen species and antioxidant protection (1). Oxidative reactions most frequently involving free radical intermediates which play an important role in the oxidative stress processes. Additionally, oxidative reactions participate in both direct and indirect amplification of inflammatory responses or in activation of signaling cascades mediating proliferation, differentiation and cell death. Numerous reports have implicated free radical oxidations and decreased antioxidant defenses in patients with uremia and hemodialysis (HD) $(2,3)$.

Various mechanisms explained for increased oxidative stress in $\mathrm{HD}$, consisting of activation of oxidative metabolism in phagocytes through complement-activating membranes (4-6). In addition, bloodmembrane interaction triggers circulating neutrophils to produce numerous amounts of reactive oxygen species (ROS), including

\section{Key point}

In a study on 85 hemodialysis patients, in individuals under 40 years, a positive and significant correlation between albumin and 8-hydroxy-2'-deoxyguanosine was detected.

superoxide anion, hydrogen peroxide, hydroxyl radical and hypochlorouacid, while plasma levels of glutathione and vitamins $\mathrm{C}$ and $\mathrm{E}$ decreased in these patients (7-9). ROS cause damage to cellular constituents, including membrane lipids, proteins, and DNA. DNA is not as well protected against oxidation by small-molecular-weight antioxidants and free radical scavenging enzymes as membrane lipids and proteins (5).

8-hydroxy-2-deoxyguanosine (8-OHdG) is formed from deoxyguanosine in DNA by hydroxyl free radical. 8-OHdG is one of the most abundant oxidative products of DNA and is known as one of the most reliable markers of oxidative DNA damage because guanosine is the most oxidized among the

Copyright $\odot 2020$ The Author(s); Published by Society of Diabetic Nephropathy Prevention. This is an open-access article distributed under the terms of the Creative Commons Attribution License (http://creativecommons.org/licenses/by/4.0), which permits unrestricted use, distribution, and reproduction in any medium, provided the original work is properly cited. 
DNA nucleobases(10-12). Recently it was shown that 8-OHdG content in leukocyte DNA is a useful biomarker of oxidative stress which is the consequence of uremia, since it is further augmented by complement-activating membranes during HD procedure(5).

Recent investigations found that the levels of 8 -OHdG and CRP were, on average, 2.5-2.7-fold greater in the HD patients than those in the healthy control subjects (13). Furthermore, levels of 8-OHdG are significantly associated with both $\mathrm{CAD}$ and other types of atherosclerotic processes including stroke, peripheral artery disease, and carotid atherosclerosis (12). In the study by Dai et al (14) levels of 8-OHdG was associated with increased all-cause mortality risks in individuals with a wide range of estimated glomerular filtration rate (eGFR) and its association was independent of inflammation.

Plasma concentrations of 8-OHdG, interleukin 6 (IL6), and high-sensitivity C-reactive protein (hs-CRP) were higher in HD patients than in the PD while a recent study demonstrated a mortality predictive effect for plasma 8-OHdG in HD patients (15). Moreover, another study indicated that the 8-OHdG content in leukocyte DNA was significantly increased in patients with Leber's hereditary optic neuropathy. Oxidative stress has a key role in the pathogenesis of Leber's hereditary optic neuropathy (16).

Likewise, a meta-analysis showed that highly expressed 8-OHdG in tumor tissues may be a predictor of prognosis in most solid tumors. They detected that 8 -OHdG expression has a prognostic value in cancer patients (17).

End-stage renal disease (ESRD) patients undergoing dialysis have a substantially increased risk of cardiovascular morbidity and mortality (15-18).

Developing countries in Southeast Asia have a high burden of chronic kidney disease (CKD) and ESRD (19).

Keith et al have shown the burden of ESRD will increase in the United States population through 2030 due to demographic, clinical, and lifestyle shifts in the population (20).

\section{Objectives}

The objective of this present study was to determine the association of $8-\mathrm{OHdG}$ with various demographic and biochemical parameters in HD patients. We also sought to investigate the factors associated with oxidative stress levels as a marker of mortality in HD patients.

\section{Patients and Methods}

\section{Patients and protocol}

In this study, 85 ESRD patients (58 were men) undergoing HD in Amin hospital in Isfahan (2019) were examined regarding relationship of serum $8-\mathrm{OHdG}$ with various demographic and biochemical parameters. The mean \pm SD age of the patients was $62.8 \pm 13.76$ years (Table 1 ). The average dose of dialysis was $10.87 \pm 2.22 \mathrm{~h} /$ wk $(18-4 \mathrm{~h} /$ wk). The most underlying causes of renal diseases were diabetes and hypertension respectively (Table 2). Access to dialysis
Table 1. Clinical characteristics of the patients

\begin{tabular}{ll}
\hline Parameters & \\
\hline Patients & 85 \\
Age $(\mathrm{y})$, mean $\pm \mathrm{SD}$ & $62.8 \pm 13.76$ \\
$\mathrm{BMI}\left(\mathrm{kg} / \mathrm{m}^{2}\right)$, mean $\pm \mathrm{SD}$ & $24.4 \pm 4.25$ \\
Dose of dialysis $(\mathrm{h} / \mathrm{wk})$, mean $\pm \mathrm{SD}$ & $10.87 \pm 2.22$ \\
\hline
\end{tabular}

Table 2. The frequency and percentage of underlying causes leading to dialysis in patients

\begin{tabular}{lc}
\hline Underlying causes leading to dialysis in patients & Number \\
\hline Diabetes & 40 \\
Hypertension & 24 \\
Diabetes and hypertension (combined) & 5 \\
Lupus & 2 \\
Glomerulonephritis & 2 \\
Autosomal dominant polycystic kidney disease & 1 \\
Nephropathy (IgA) & 2 \\
Trauma & 1 \\
Unknown & 6 \\
Cholangiocarcinoma and cancer & 2 \\
Total & 85 \\
\hline
\end{tabular}

in 39 patients was arterial venous fistulas (AVFs) and in 46 patients was HD catheter. The mean body mass index (BMI) of the studied patients was $24.4 \pm 4.25 \mathrm{~kg} / \mathrm{m}^{2}$.

The criteria of the study were lack of systemic infections, under HD therapy for at least six months and willingness to participate in the study by signing the consent form.

\section{Laboratory assessments}

Around $10 \mathrm{cc}$ of venous blood samples was obtained after an overnight fast and before the dialysis session, then immediately transferred to the laboratory. The serum supernatant removed by 20 minutes centrifugation at the speed of 2000 to $3000 \mathrm{rpm}$ then the samples were stored frozen at $-20^{\circ} \mathrm{C}$ until analysis. Serum $8-\mathrm{OHdG}$, was measured by ELISA (enzyme-linked immunosorbent assay) method (BT kit, China). This assessment was based on an antigen-antibody response by the sandwich method. First, micro-titer holes were covered with proprietary antibodies, further samples and standards, plus 8-hydroxy2'-deoxyguanosine (8-OHdG) antibody and conjugate enzyme were added to the sinks and then incubated for 60 minutes at $37^{\circ} \mathrm{C}$. Then after, biotin bounded to these antibodies formed immune complexes by binding to streptavidin-horseradish peroxidase. Unbound enzymes after incubation for 10 minutes and 5 times rinsing were removed. To continue, the reaction stop solution was added. In the end, by adding the acid, color of the solution changed to yellow. Eventually, the read absorption intensity due to the color production had a direct relationship with the concentration of 8-OHDG. The 8-OHdG ranging with assay range of $0.5 \mathrm{ng} / \mathrm{mL} \rightarrow 100 \mathrm{ng} / \mathrm{mL}$ and sensitivity of 
$0.25 \mathrm{ng} / \mathrm{mL}$. Accordingly, levels of vitamin D, magnesium, and intact PTH were measured with standard kits. Other clinical and biochemical variables were gathered from patients' files.

\section{Ethical issues}

Human rights were respected in accordance with the Helsinki Declaration 1975, as revised in 1983. The ethical committee of Isfahan University of Medical Sciences (Ethical code\# IR.MUI.MED.REC.1398.061) approved the study. Informed consent was taken from the patients. Besides, this study was extracted from M.D., thesis of Fatemeh Goli In the department of internal medicine at this university (Thesis \# 398069).

\section{Statistical analysis}

To analyze the data we used SPSS 22 software and independent $t$ tests, variance analysis, Pearson's correlation coefficient or their non-parametric equivalent. The minimal level of significance chosen for determining association of 8 -OHdG with various demographic and biochemical parameters was $P<0.05$. All data are presented as means \pm SD (Table 3 ).

\section{Results}

In our study, mean of $8-\mathrm{OHdG}$ levels was $73.806 \pm 38.89$ $\mathrm{ng} / \mathrm{mL}$, while the levels of $8-\mathrm{OHdG}$ were higher in female, diabetics and individuals dialyzed with catheters; however these differences were not significant $(P>0.05$, Tables 4 and 5). Our study showed no significant correlation between serum levels of $8-\mathrm{OHdG}$ and other biochemical parameters and blood indices. There was also no significant correlation between serum levels of $8-\mathrm{OHdG}$ and $\mathrm{Kt} / \mathrm{V}$ and urea reduction rate (Table 3 ). Pearson's correlation coefficient indicated no significant correlation between serum 8-OHdG level and age of patients, duration of HD too (Table 6). Comparison of mean serum 8-OHdG levels in groups with BMI and in patients with various underlying causes leading to HD did not show a significant difference (Tables 7 and 8). Comparison of serum 8-OHdG levels between patients with AVF and HD catheter did not show a significant difference (Table 5).

Our study showed a significant negative correlation between serum albumin and $8-\mathrm{OHdG}$ in the subgroups of the patients which their underlying cause of renal disease was diabetes or hypertension (and combined) $(r=-0.911$, $P=0.031$ for all). In other groups with other underlying

Table 3. Mean, standard deviation (SD), minimum and maximum level of laboratory parameters in the studied patients and its relationship with 8-OHDG serum levels

\begin{tabular}{|c|c|c|c|c|c|}
\hline Laboratory parameters & Mean & SD & Minimum & Maximum & Correlation with serum level $8-\mathrm{OHdG}$ ** \\
\hline 8-OHDG (ng/mL) & 73.806 & 38.89 & 8 & 179 & - \\
\hline Calcium (mg/dL) & 8.322 & 0.62 & 6.5 & 10.3 & $r=-155, P=0.157$ \\
\hline Magnesium (mg/dL) & 2.2436 & 0.29 & 1.60 & 2.9 & $r=131, P=0.232$ \\
\hline Vitamin D (ng/mL) & 17.648 & 10.6 & 6.3 & 62.9 & $r=0.049, P=0.653$ \\
\hline Intact PTH (pg/mL) & 348.005 & 251.8 & 56.0 & 1818 & $r=0.026, P=0.815$ \\
\hline Phosphorus (mg/dL) & 4.804 & 1.48 & 12 & 10.1 & $r=0.076, P=0.194$ \\
\hline Alkaline phosphatase (U/L) & 401.359 & 281.49 & 2.5 & 1968 & $r=0.129, P=0.240$ \\
\hline Albumin (g/dL) & 3.920 & 0.51 & 2.7 & 5.1 & $r=0.117, P=0.285$ \\
\hline $\mathrm{B} \cup \mathrm{N}(\mathrm{mg} / \mathrm{dL})$ & 52.271 & 18.01 & 24 & 123 & $r=0.122, P=0.264$ \\
\hline Creatinine (mg/dL) & 7.119 & 2.56 & 2.2 & 16 & $r=0.128, P=0.242$ \\
\hline FBS (mg/dL) & 125.953 & 76.4 & 51.0 & 449 & $r=0.048, P=0.665$ \\
\hline Cholesterol (mg/dL) & 133.965 & 36.85 & 70 & 242 & $r=0.083, P=0.450$ \\
\hline Triglyceride (mg/dL) & 116.318 & 83.02 & 29 & 510 & $r=-0.030, P=0.786$ \\
\hline LDL-C (mg/dL) & 72.800 & 24.05 & 26 & 146 & $r=0.057, P=0.603$ \\
\hline HDL-C (mg/dL) & 33.659 & 11.59 & 15 & 76 & $r=-0.065, P=0.553$ \\
\hline WBC count $\left(/ \mathrm{mm}^{3}\right)$ & 6631.765 & 2185.73 & 2000.0 & 12500 & $r=-0.050, P=0.649$ \\
\hline RBC (million/mm³) & 3.6629 & 0.66 & 1.59 & 06.5 & $r=0.050, P=0.653$ \\
\hline Platelet count (/mm3) & 183952.9 & 68308.63 & 31000.0 & 496000 & $r=-0.061, P=0.582$ \\
\hline Hemoglobin (g/dL) & 10.547 & 2.2 & 1.9 & 14.6 & $r=-0.014, P=0.898$ \\
\hline Hematocrit (\%) & 33.11 & 5.73 & 16.4 & 44.6 & $r=0.067, P=0.542$ \\
\hline Iron serum $(\mu \mathrm{g} / \mathrm{dL})$ & 115.9 & 182.48 & 8 & 947.8 & $r=-0.051, P=0.642$ \\
\hline $\operatorname{TIBC}(\mu \mathrm{g} / \mathrm{dL})$ & 284.28 & 107.46 & 3.8 & 829 & $r=-0.054, P=0.626$ \\
\hline Ferritin $(\mu \mathrm{g} / \mathrm{dL})$ & 418.8 & 237.42 & 18 & 802 & $r=0.071, P=0.519$ \\
\hline $\mathrm{Kt} / \mathrm{V}^{*}$ & 1.249 & 0.35 & 0.46 & 2.1 & $r=0.027, P=0.809$ \\
\hline Urea reduction rate & 0.64 & 0.11 & 0.32 & 0.98 & $r=-0.049, P=0.658$ \\
\hline GFR mL/min/1.73m² & 8.179 & 4.43 & 2.8 & 28.3 & $r=-0.159, P=0.147$ \\
\hline
\end{tabular}

* Kt/V; number used to quantify hemodialysis and peritoneal dialysis treatment adequacy, ** Pearson's correlation. 
Table 4. Mean and standard deviation of $8-\mathrm{OHdG}$ serum level and comparison between males and females

\begin{tabular}{llccc}
\hline \multirow{2}{*}{ Gender } & Number & \multicolumn{2}{c}{$\mathbf{8 - O H d G}(\mathbf{n g} / \mathbf{m L})$} & \multirow{2}{*}{ P Value } \\
\cline { 3 - 4 } & & Mean & SD & \\
\hline Male & 58 & 72.41 & 37.9 & 0.631 \\
Female & 27 & 76.80 & 41.4 & t test \\
\hline
\end{tabular}

Table 5. Comparison of mean serum 8-OhdG levels based on hemodialysis access

\begin{tabular}{|c|c|c|c|c|}
\hline \multirow{2}{*}{ Gender } & \multirow{2}{*}{ Number } & \multicolumn{2}{|c|}{ 8-OHdG (ng/mL) } & \multirow{2}{*}{ P Value } \\
\hline & & Mean & SD & \\
\hline AVF & 39 & 73.04 & 36.7 & \multirow{2}{*}{$\begin{array}{l}0.896 \\
t=-0.165\end{array}$} \\
\hline $\begin{array}{l}\text { Hemodialysis } \\
\text { catheter }\end{array}$ & 46 & 74.45 & 41.1 & \\
\hline
\end{tabular}

Table 6. Comparison of 8-OHdG serum levels in different age groups

\begin{tabular}{lcccc}
\hline Age $(\mathbf{y})$ & Number & 8-OHdG $(\mathbf{n g} / \mathbf{m l})$ & $\begin{array}{c}\text { Degrees of } \\
\text { freedom }\end{array}$ & P value \\
\hline$\leq 40$ & 6 & $94.50 \pm 43.5$ & & \\
$41-60$ & 29 & $75.95 \pm 44.9$ & 3 & 0.530 \\
$61-80$ & 41 & $70.19 \pm 34.8$ & & \\
$\geq 81$ & 9 & $94.05 \pm 43.5$ & & \\
\hline
\end{tabular}

Table 7. Comparison of mean serum 8-OHdG levels in individuals with different BMI

\begin{tabular}{lcccc}
\hline $\begin{array}{l}\text { BMI ( kg/ } \\
\left.\mathbf{m}^{2}\right)\end{array}$ & Number & $\mathbf{8 - O H d G ~ ( n g / m l )}$ & $\begin{array}{c}\text { Degrees of } \\
\text { freedom }\end{array}$ & $\boldsymbol{P}$ value \\
\hline$\leq 20$ & 14 & $65.90 \pm 38.8$ & & \\
$20-24.99$ & 36 & $76.38 \pm 38.2$ & 3 & 0.825 \\
$25-29.99$ & 28 & $75.71 \pm 41.7$ & & \\
$\geq 30$ & 7 & $68.68 \pm 36.0$ & & \\
\hline
\end{tabular}

diseases, no significant correlation was observed between albumin and level of 8 -OHdG $(P>0.05)$.

In the age group under 40 years, a positive and significant correlation was observed between albumin and 8-OHdG
( $\mathrm{r}=0.838, P=0.037)$. In other age groups, no significant correlation was observed between albumin and 8-OHdG.

\section{Discussion}

In this study, no significant correlation between serum 8-OHdG levels and various demographic, biochemical parameters in HD patients was observed; however, in HD patients with diabetes and hypertension (or combined), we found a significant reverse correlation between albumin and 8-OHdG. In the age group under 40 years, we also found a positive and significant correlation between albumin and 8-OHdG.

Albumin exists in both reduced and oxidized forms in systemic circulation and the reduced form of the human serum albumin is lower in patients with hepatic disorders, diabetes, and renal diseases $(21,22)$. Toyokuni et el showed the increased formation of serum 4-hydroxy-2-nonenal (HNE)-modified albumin in type 2 diabetic outpatients in the milieu between liver and vascular lumina, indicating the presence of oxidative stress (23). Albumin is the most abundant circulating protein in plasma, exerts important antioxidant activities by multiple-binding sites and free radical-trapping properties. In general, albumin constitutes the major plasma protein target of oxidant stress. Koch et al postulated that a biological compound could constitute a causative agent in a disease that appears to be fulfilled by oxidized albumin. If important beneficial actions are exerted by native albumin, very detrimental effects can be provoked by oxidized form of the protein and acting as a biomarker of oxidative stress (24-26).

In contrast to our finding, Morishita et al showed that plasma prorenin levels was associated with plasma 8-OHdG level. Plasma prorenin may contribute to increased oxidative stress in non-diabetes mellitus- HD patients (27).

Recent studies showed a significant increase in serum 8-OHdG in HD patients compared to normal subjects. These studies also showed serum $8-\mathrm{OHdG}$ was positively correlated with the patients' age but not with the duration of HD $(13,28)$. Additionally, serum 8-OHdG was correlated with the severity of renal anemia and recombinant human erythropoietin (rHuEPO) dose. In contrast, nutritional

Table 8. Comparison of mean serum 8-OHdG levels based on primary chronic kidney disease causes

\begin{tabular}{|c|c|c|c|c|}
\hline The underlying cause & Number & 8-OHdG (ng/mL) & Degrees of freedom & $P$ value \\
\hline Diabetes & 40 & $70.90 \pm 38.4$ & & \\
\hline Hypertension & 24 & $78.32 \pm 45.3$ & & \\
\hline Diabetes and hypertension (combined) & 5 & $60.20 \pm 30.8$ & 10 & 0.584 \\
\hline Systemic lupus erythematosus & 2 & $48.50 \pm 16.2$ & & \\
\hline Glomerulonephritis & 2 & $114.50 \pm 7.7$ & & \\
\hline Autosomal dominant polycystic kidney disease & 1 & 92 & & \\
\hline Nephropathy (IgA) & 2 & $77.0 \pm 46.6$ & & \\
\hline Trauma & 1 & 127 & & \\
\hline Unknown & 6 & $85.4 \pm 26.6$ & & \\
\hline Cholangiocarcinoma and cancer & 2 & $45.50 \pm 7.7$ & & \\
\hline Total & 85 & $73.80 \pm 38.89$ & & \\
\hline
\end{tabular}


and inflammatory status did not correlate with blood 8-OHdG.

These findings suggest that increased oxidative stress may be associated with rHuEPO hyporesponsiveness in HD patients (28).

In line with our results, Dai et al showed that there were no significant associations between 8-OHdG, age, gender, DM, mean arterial blood pressure and BMI. They showed that serum 8-OHdG was negatively related with estimated GFR and positively was associated with inflammatory markers such as hsCRP, IL-6, TNF, endothelial function marker (VCAM-1) and iron status (ferritin) (14). Avci et al concluded that albumin and hemoglobin had an inverse relation with $8-\mathrm{OHdG}$ which is in agreement with our finding $(14,29)$.

If we can identify the factors that affect oxidative stress in dialysis patients, we can prevent common complications and mortality in these patients as well. For example, some studies have shown that intravenous iron sucrose provoked oxidative damage to peripheral blood lymphocyte DNA in HD patients, especially among those with high levels of ferritin $(30,31)$. Intravenous iron therapy exhibited the pro-oxidant property in HD patients and led to ROS overproduction and impairment of the antioxidant defense (32). The progression and severity of CKD are strongly associated with exacerbation of the inflammatory state and oxidative stress that cause serious systemic complications including cardiovascular disease, anemia and mineral disorders. Many of antioxidant agents have been shown to reduce the inflammatory state by modulation of the nuclear factor kappa-light-chain-enhancer of activated B cells (NF- $\kappa \mathrm{B})$-dependent pathway, reducing the level of cytokines and pro-inflammatory enzymes (33). The antioxidant treatment strategy consists of replenishing vitamin $\mathrm{C}$, vitamin $\mathrm{E}$, selenium, $\mathrm{N}$-acetylcysteine and coenzyme Q10. On-line HD, a biocompatible vitamin E coated dialysis membrane and an ultra-pure solution for $\mathrm{HD}$ prevents oxidative stress and can prevent the development of cardiovascular diseases and morbidity, mortality (34-37).

\section{Limitations}

Since dialysis patients are usually treated with various drugs and antioxidants that may affect their oxidative stress levels, because this issue is very important and should be considered in the selection of patients. Given that the effect of dialysis membrane on oxidative stress has been mentioned in a number of studies, patients who are selected should be treated with only one specific type of dialysis membrane. Accordingly, published studies used various methods for 8-OHdG measurement which make the results to be different, while a validated standard technique has not yet been identified. Furthermore, we examined the level of 8-OHdG in dialysis patients before dialysis while further studies are needed to evaluate together the oxidative stress before and after dialysis in the patients undertaking HD treatment. One study has shown the increase in the levels of $8-\mathrm{OHdG}$ (marker of DNA damage) and malondialdehyde (marker of lipid damage) after HD in diabetic nephropathy (DN) and nonDN groups but decrease was observed in the asymmetric dimethylarginine (marker of endothelial damage) levels. This finding needs more attention (29). One study showed that measurement of 8 -OHdG in the plasma rather than tissue of diabetic rats is a more useful biomarker of oxidative DNA damage (38). However more studies are needed to compare 8-OHdG levels in blood and leukocyte DNA. While one of the factors influencing the level of 8 -OHdG is genotype of patients; we did not evaluate it in our study and it can be considered in future studies that focous on the factors affecting oxidative stress. Tarng et al have shown that the extent of oxidative DNA damage among chronic HD patients not only was influenced by overproduction of ROS resulting from leukocyte contacts with complement-activating membranes and by impaired antioxidant defense mechanisms but also is genetically determined. The $8 \mathrm{OHdG}$ concentration in peripheral blood leukocytes is dependent on the gene hOGG1 1245CgG polymorphism. The hOGG1 inactivates glycosylation of $8 \mathrm{OHdG}$. The authors report that the 8 -OHdG concentration is about two times higher in patients with the 1245GG genotype in comparison with the 1245CG and 1245CC genotypes $(13,39)$.

\section{Conclusion}

We found a significant positive correlation between serum albumin and serum 8-OHdG level in the age group under 40 years. Similarly, in HD patients with diabetes and hypertension (or combined) a reverse correlation of serum albumin and serum 8-OHdG level was detected, which shows the association of serum albumin as the highest plasma protein with oxidative stress. Our study, however, requires further research to investigate the relationship between serum 8-OHdG levels and serum albumin types as reduced and oxidized forms, according to the factors affecting the level of plasma proteins.

\section{Acknowledgements}

The authors thank Mohammad-Javad Tarrahi, PhD (Isfahan University of Medical Sciences), and Mehrdad Zahmatkesh MSc (Semnan University of Medical Sciences), for conducting the statistical analysis.

Authors' contribution

Data gathering and the primary draft was prepared by FG. HN edited the manuscript. Both authors read and signed the final manuscript.

Conflicts of interest

The authors declare that they have no competing interests.

Ethical considerations

Ethical issues (including plagiarism, data fabrication, double publication) have been completely observed by the authors. 


\section{Funding/Support}

The study was partially funded by Isfahan University of Medical Sciences (Grant\#16808).

\section{References}

1. Akagi S, Nagake $\mathrm{Y}$, Kasahara J, Sarai A, Kihara T, Morimoto $\mathrm{H}$, Yano A, et al. Significance of 8-hydroxy-2'-deoxyguanosine levels in patients with chronic renal failure. Nephrology (Carlton). 2003;8(4):192-195. doi: 10.1046/j.14401797.2003.00163.x

2. Wratten ML, Tetta C, Ursini F, Sevanian A. Oxidant stress in hemodialysis: prevention and treatment strategies. Kidney Int Suppl. 2000;76:S126-S132. doi: 10.1046/j.15231755.2000.07616.x

3. Witko-Sarsat V, Friedlander $M$, Capeillère-Blandin $C$, et al. Advanced oxidation protein products as a novel marker of oxidative stress in uremia. Kidney Int. 1996;49:1304-13. doi:10.1038/ki.1996.186

4. Himmelfarb J, Ault KA, Holbrook D, Leeber DA, Hakim RM. Intradialytic granulocyte reactive oxygen species production: a prospective, crossover trial. J Am Soc Nephrol. 1993;4:178186.

5. Tarng DC, Huang TP, Wei YH, Liu TY, Chen HW, Wen Chen T, et al. 8-hydroxy-2'-deoxyguanosine of leukocyte DNA as a marker of oxidative stress in chronic hemodialysis patients. Am J Kidney Dis. 2000;36:934-44. doi: 10.1053/ajkd.2000.19086.

6. Luciak M, Trznadel K. Free oxygen species metabolism during haemodialysis with different membranes. Nephrol Dial Transplant. 1991;6 Suppl 3:66-70.

7. Loughrey CM, Young IS, Lightbody JH, McMaster D, McNamee PT, Trimble ER. Oxidative stress in haemodialysis. QJM. 1994;87:679-683.

8. Ceballos-Picot I, Witko-Sarsat V, Merad-Boudia M, Nguyen AT, Thévenin $M$, Jaudon $M C$, et al. Glutathione antioxidant system as a marker of oxidative stress in chronic renal failure. Free Radic Biol Med. 1996;21:845-853. doi: 10.1016/08915849(96)00233-x.

9. Peuchant E, Carbonneau MA, Dubourg L, Thomas MJ, Perromat A, Vallot C, Clerc M. Lipoperoxidation in plasma and red blood cells of patients undergoing haemodialysis: vitamins A, E, and iron status. Free Radic Biol Med. 1994;16:339-346. doi:10.1016/0891-5849(94)90035-3.

10. Ames BN. Micronutrients prevent cancer and delay aging. Toxicol Lett. 1998;102-103:5-18. doi: 10.1016/s03784274(98)00269-0.

11. Leinonen J, Lehtimäki T, Toyokuni S, Okada K, Tanaka T, Hiai $\mathrm{H}$, et al. New biomarker evidence of oxidative DNA damage in patients with non-insulin-dependent diabetes mellitus. FEBS Lett. 1997;417:150-152. doi: 10.1016/s0014-5793(97)012738.

12. Di Minno A, Turnu L, Porro B, Squellerio I, Cavalca V, Tremoli E, et al. 8-Hydroxy-2-deoxyguanosine levels and cardiovascular disease: a systematic review and meta-analysis of the literature. antioxid redox signal. 2016;24:548-555. doi: 10.1089/ars.2015.6508.

13. Mastalerz-Migas A, Steciwko A, Pokorski M, Pirogowicz I, Drobnik J, Bunio A, et al. What influences the level of oxidative stress as measured by 8 -hydroxy-2'-deoxyguanosine in patients on hemodialysis? J Physiol Pharmacol. 2006;57 Suppl 4:199-205.

14. Dai L, Watanabe M, Qureshi AR, Mukai H, Machowska A, Heimbürger $\mathrm{O}$, et al. Serum 8-hydroxydeoxyguanosine, a marker of oxidative DNA damage, is associated with mortality independent of inflammation in chronic kidney disease. Eur J Intern Med. 2019;68:60-65. doi: 10.1016/j.ejim.2019.07.035.
15. Xu H, Watanabe $M$, Qureshi AR, Heimbürger O, Bárány $P$, Anderstam B, et al. Oxidative DNA damage and mortality in hemodialysis and peritoneal dialysis patients. Perit Dial Int. 2015;35:206-215. doi: 10.3747/pdi.2013.00259.

16. Yen MY, Kao SH, Wang AG, Wei YH. Increased 8-hydroxy-2'deoxyguanosine in leukocyte DNA in Leber's hereditary optic neuropathy. Invest Ophthalmol Vis Sci. 2004;45:1688-1691. doi:10.1167/iovs.03-0568

17. Qing X, Shi D, Lv X, Wang B, Chen S, Shao Z. Prognostic significance of 8-hydroxy-2'-deoxyguanosine in solid tumors: a meta-analysis. BMC Cancer. 2019;19997. doi:10.1186/ s12885-019-6189-9

18. Eknoyan G. Cardiovascular mortality and morbidity in dialysis patients. Miner Electrolyte Metab. 1999;25:100-104. doi:10.1159/000057429

19. Tang SC. ESRD: epidemiology and treatment in developing countries in Southeast Asia. Clin Nephrol. 2017;10.5414/ CNP86S199. doi:10.5414/CNP86S199

20. McCullough KP, Morgenstern $H$, Saran $R$, Herman $W H$, Robinson BM. Projecting ESRD Incidence and Prevalence in the United States through 2030. J Am Soc Nephrol. 2019;30:127-35. doi: 10.1681/ASN.2018050531

21. Atukeren P, Aydin S, Uslu E, Gumustas MK, Cakatay U. Redox homeostasis of albumin in relation to alpha-lipoic acid and dihydrolipoic acid. Oxid Med Cell Longev. 2010;3:206-13. doi: 10.4161/oxim.3.3.11786

22. Sitar ME, Aydin S, Cakatay U. Human serum albumin and its relation with oxidative stress. Clin Lab. 2013;59:945-952.

23. Toyokuni S, Yamada S, Kashima M, Ihara Y, Yamada Y, Tanaka $\mathrm{T}$, et al. Serum 4-hydroxy-2-nonenal-modified albumin is elevated in patients with type 2 diabetes mellitus. Antioxid Redox Signal. 2000;2:681-5. doi:10.1089/ars.2000.2.4-681

24. Roche M, Rondeau P, Singh NR, Tarnus E, Bourdon E. The antioxidant properties of serum albumin. FEBS Lett. 2008;582:1783-7. doi: 10.1016/j.febslet.2008.04.057.

25. Halliwell B. Albumin--an important extracellular antioxidant? Biochem Pharmacol. 1988;37:569-71. doi: 10.1016/00062952(88)90126-8.

26. Bar-Or D, Rael LT, Lau EP, Rao NK, Thomas GW, Winkler JV, et al. An analog of the human albumin $\mathrm{N}$-terminus (Asp-AlaHis-Lys) prevents formation of copper-induced reactive oxygen species. Biochem Biophys Res Commun. 2001;284:856-62. doi: 10.1006/bbrc.2001.5042.

27. Morishita Y, Hanawa S, Miki T, Sugase T, Sugaya Y, Chinda J, et al. The association of plasma prorenin level with an oxidative stress marker, 8-OHdG, in nondiabetic hemodialysis patients. Clin Exp Nephrol. 2011;15:398-404. doi: 10.1007/s10157010-0398-5

28. Kato A, Odamaki M, Hishida A. Blood 8-hydroxy-2'deoxyguanosine is associated with erythropoietin resistance in haemodialysis patients. Nephrol Dial Transplant. 2003;18:9316. doi: 10.1093/ndt/gfg070.

29. Avci E, Cakir E, Cevher SC, Yaman H, Agilli M, Bilgi C. Determination of oxidative stress and cellular inflammation in patients with diabetic nephropathy and non-diabetic nephropathy being administered hemodialysis treatment due to chronic renal failure. Ren Fail. 2014;36:767-773. doi: 10.3109/0886022X.2014.890841.

30. Salahudeen AK, Oliver B, Bower JD, Roberts LJ 2nd. Increase in plasma esterified $\mathrm{F}$ 2-isoprostanes following intravenous iron infusion in patients on hemodialysis. Kidney Int. 2001;60:1525-31. doi:10.1046/j.1523-1755.2001.00976.x

31. Tovbin D, Mazor D, Vorobiov M, Chaimovitz C, Meyerstein $\mathrm{N}$. Induction of protein oxidation by intravenous iron in hemodialysis patients: role of inflammation. Am J Kidney Dis. 
2002;40(5):1005-1012. doi: 10.1053/ajkd.2002.36334.

32. Kuo KL, Hung SC, Wei YH, Tarng DC. Intravenous iron exacerbates oxidative DNA damage in peripheral blood lymphocytes in chronic hemodialysis patients. J Am Soc Nephrol. 2008;19:1817-1826. doi: 10.1681/ASN.2007101084

33. Rapa SF, Di lorio BR, Campiglia P, Heidland A, Marzocco S. Inflammation and oxidative stress in chronic kidney diseasepotential therapeutic role of minerals, vitamins and plantderived metabolites. Int J Mol Sci. 2019;21:263. doi:10.3390/ ijms21010263

34. Antić S, Draginić N, Nikolić T, Jeremić N, Petrović D. Oxidative stress in hemodialysis patients: pathophysiological mechanisms, clinical consequences and basic principles of treatment. Serbian J Exp Clin Res. 2019; In Press.

35. Tarng DC, Huang TP, Liu TY, Chen HW, Sung YJ, Wei YH. Effect of vitamin E-bonded membrane on the 8-hydroxy 2'-deoxyguanosine level in leukocyte DNA of hemodialysis patients. Kidney Int. 2000;58:790-9. doi: 10.1046/j.15231755.2000.00228.x.
36. Domenici FA, Vannucchi MT, Jordão AA Jr, Meirelles MS, Vannucchi H. DNA oxidative damage in patients with dialysis treatment. Ren Fail. 2005;27:689-94. doi: 10.1080/08860220500242678.

37. Tarng DC, Liu TY, Huang TP. Protective effect of vitamin C on 8-hydroxy-2'-deoxyguanosine level in peripheral blood lymphocytes of chronic hemodialysis patients. Kidney Int. 2004;66:820-31. doi: 10.1111/j.1523-1755.2004.00809.x.

38. Park KS, Kim JH, Kim MS, Kim JM, Kim SK, Choi JY, et al. Effects of insulin and antioxidant on plasma 8-hydroxyguanine and tissue 8-hydroxydeoxyguanosine in streptozotocin-induced diabetic rats. Diabetes. 2001;50:2837-41. doi: 10.2337/ diabetes.50.12.2837

39. Tarng DC, Tsai TJ, Chen WT, Liu TY, Wei YH. Effect of human OGG1 1245C-->G gene polymorphism on 8-hydroxy-2'deoxyguanosine levels of leukocyte DNA among patients undergoing chronic hemodialysis. J Am Soc Nephrol. 2001;12:2338-2347. 